\title{
ENGINEERING GRADUATES' PERCEPTION OF COMPETENCIES AND PREPARATION TO THE LABOR MARKET TRANSITION
}

\author{
Sílvia Monteiro ${ }^{1}$, Leandro S. Almeida ${ }^{2}$, Rosa M. Vasconcelos ${ }^{3}$ \\ ${ }^{1}$ Research Centre in Education, University of Minho (PORTUGAL) \\ ${ }^{2}$ Institute of Education, University of Minho (PORTUGAL) \\ ${ }^{3}$ School of Engineering, University of Minho (PORTUGAL)
}

\begin{abstract}
Current models of employability are rather broad and complex, including not only a set of skills as determinant factors in employability, but also a subjective dimension that considers individual selfbeliefs and attitudes. Under this framework, the perception of competencies developed during Higher Education were explored. This study intended to understand how engineering graduates evaluate the competencies developed during higher education and how this relates with the perception of preparation to the labor market transition. For that purpose, a sample of 332 Portuguese senior students taking an engineering masters' degree filled a questionnaire. The obtained results pointed to (i) a lower evaluation concerning practical competencies comparing with other theoretical, transversal or employability competencies; (ii) practical competencies, together with communication, methodological and socioemotional competencies appear as the most important predictors of labor market transition. These findings enhance the importance of the integration of a stronger practical component in engineering curriculum as a way to better prepare graduates and to promote employability.
\end{abstract}

Keywords: engineering graduates; competencies; higher education; labor market transition.

\section{INTRODUCTION}

The development of competencies that prepare graduates for the labor market transition is one of the current missions assigned to Higher Education institutions [1]. In an effort to foster Higher Education quality, a substantial body of research has focused on a institutional approach to employability in an attempt to establish the relationship between the competencies developed during Higher Education studies and graduates employability [2]-[7]. In turn, individual approaches to employability assume the existence of proactive characteristics that enable individuals to play an active role in their own employability, taking on a narrow interaction between the self and the environment, as a requirement to be "employable".

Current employability models, such as the USEM model (Understanding; Skills; Efficacy beliefs; and Metacognition) [8] and the CareerEDGE model (Experience; Degree subject knowledge, understanding and skills; Generic skills; and Emotional intelligence) [9] provide a crucial link between employability and knowledge, understanding, skills, experience, and personal attributes. This means that, according with that perspectives, not only the set of objective competencies developed, but also the perceptions of mastering such competencies are important to understand future graduates' employability. The factors that underline how individuals perceive their own employability and the competencies related with that, is still a subject under-reserached [10], [11], particularly in the Engineering field [9].

In a report about Engineering Education in the $21^{\text {st }}$ century, Spinks and colleagues (2006) [13] recommend the need to develop skills beyond the narrowly technical in order to promote the perception of "work-ready" when graduates move to professional context after their graduation course. Specifically, the authors argue for the need to combine technical expertise with practical ability, together with interpersonal skills, as a fundamental requisite to operate successfully in business environment. The strong emphasis of the report conclusions turns around the need to improve graduates' ability to apply their knowledge to industry problems. Similar results were reported by Jollands and colleagues (2012) [14], which point to skill gaps among Enginerring graduates concerning problem solving, report-writing skills and ability to recognise ethical implications of projects. When graduates are asked about difficulties they encountered during transition to the labor market, issues such as taking on new responsibilities, performing under pressure, dealing with 
superiors and communicating with people from diverse backgrounds, emerged among the most cited [9].

The purpose of this study is (i) to explore how Engineering graduates from a Portuguese university evaluate the competencies acquired by the end of their master courses (ii) to explore how these Engineering graduates evaluate their preparedness for work transition. Lastly, (iii) to explore if there is any association between higher positive perceptions competencies, and the preparation for work transition.

\section{METHODS}

\subsection{Participants}

A convenience sample of 332 students (33\% female) from a public university situated in the North of Portugal participated in this study. Students attended the senior year of masters' degree from different Engineering courses. The average age is 22 years $(S D=3.43)$, ranging between 20 and 48 years. At the moment of data collection, 19 participants $(6 \%)$ had the status of worker student.

\subsection{Measures}

For the purpose of this paper, two items from a larger questionnaire were selected, which focus on the evaluation of the training received during Engineering studies and preparation to the transition to the labor market. The questions selected for analysis were the following: (1) "Overall, how do you rate the quality of the college education you received regarding each of the following areas of knowledge/competencies?" (5-point Likert scale, ranging from 1 "very weak" to 5 "very strong"); (2) "Considering the college education you received, how do you rate your overall preparation for the transition to the labor market?" (5-point Likert scale, ranging from 1 "not prepared at all" to 5 "very well prepared").

The several competencies evaluated represent four main groups: theoretical competencies - focusing on theoretical contents learned in the course; practical competencies - regarding technical preparation to perform a job; transversal competencies - a set of competencies that are transferable to the various professional activities. For this group, we followed the classification presented by García-Aracil and Velden (2008) [7], which integrates communication competencies - to speak and write clearly and effectively; methodological competencies - to know how to use tools and resources, as analyse problems, use information technologies, speak foreign languages, etc.; interpersonal competencies to know how to work and interact with others, how to lead, manage conflicts, work in a team, motivate others, etc.; participative competencies - referring to initiative, autonomy, self-motivation, decision making, identification of opportunities, innovation, lifelong learning etc.; organizational competencies to know how to organize for tasks, how to plan, collect and process information, to be attentive to detail, etc.); socioemotional competencies - to know how to manage emotions as tolerate stress, have self-confidence, self-control, etc.; generic competencies - referring to general knowledge, sense of citizenship, ethical awareness, etc.; and lastly, employability competencies - regarding job search strategies, adaptability and capacity to take career decisions.

\subsection{Procedures}

The questionnaire was applied in classroom context, after the explanation of the aims of the research project. After obtaining the agreement for students' voluntary participation, participants signed an informed consent. Anonymity and confidentiality of the collected information was assured. Data collected were analysed with the software package used for statistical analysis, IBM SPSS (version 23.0). 


\section{RESULTS}

Table 1 presents the average ratings and standard deviations concerning graduates' perceptions of competencies developed during their Engineering studies and perception of preparation to labor market transition. The overall results show that both male and female graduates considered that practical competencies are those that were less developed during their higher education studies, followed by employability competencies. Contrary, interpersonal competencies represent those with higher ratings for male graduates and for the total group, while organizational competencies are highly scored in the case of female graduates. Male graduates have more positive scores than female graduates in the overall competencies, with exception for communication, organizational and employability competencies. Concerning the perception of preparation to labor transition, the generality of the participants scored around the middle of the scale, with a positive difference favoring female graduates. Moreover, the score obtained for the perception of preparation to LM transition is slightly below graduates' perceptions about the competencies developed during their Engineering program.

Table 1 - Means and standard deviation of competencies by gender

\begin{tabular}{lccc}
\hline & \multicolumn{2}{c}{ Gender } & \\
\cline { 2 - 3 } Competencies & $\begin{array}{c}\text { Male } \\
(\mathrm{n}=212) \\
\text { Mean (DP) }\end{array}$ & $\begin{array}{c}\text { Female } \\
(\mathrm{n}=110) \\
\text { Mean (DP) }\end{array}$ & $\begin{array}{c}\text { Total } \\
(\mathrm{n}=332) \\
\text { Mean (DP) }\end{array}$ \\
\hline Theoretical & $3.76(.72)$ & $3.63(.61)$ & $3.72(.68)$ \\
Practical & $3.21(.94)$ & $2.99(.82)$ & $3.14(.91)$ \\
Communication & $3.56(.75)$ & $3.64(.66)$ & $3.59(.72)$ \\
Methodological & $3.50(.83)$ & $3.35(.67)$ & $3.44(.78)$ \\
Interpersonal & $3.79(.80)$ & $3.77(.66)$ & $3.78(.76)$ \\
Participative & $3.61(.74)$ & $3.58(.59)$ & $3.60(.70)$ \\
Organizational & $3.60(.81)$ & $3.85(.59)$ & $3.68(.75)$ \\
Socioemotional & $3.43(.91)$ & $3.38(.91)$ & $3.42(.93)$ \\
Generic & $3.53(.77)$ & $3.44(.84)$ & $3.51(.79)$ \\
Employability & $3.24(.94)$ & $3.15(.85)$ & $3.21(.92)$ \\
Preparation to LM transition & $3.00(.83)$ & $3.12(.59)$ & $3.05(.77)$ \\
\hline
\end{tabular}

Table 2 presents the regression analysis performed in order to explore which competencies are relevant to the explanation of the perceptions of preparation to labor market transition. Gender and age were also included as predictors.

Regarding graduates' perceptions of preparation to labor market transition, the obtained results demonstrated that being a female student seem to have significant influence on this variable. In turn, age did not evidence any significant relationship with the preparation to labor market transition. Concerning the competencies developed during Engineering programs, several competencies seem to be relevant to the understanding of graduates' perceptions of preparation to labor market transition. Specifically, practical competencies, together with communication competencies, appear as significant predictors of graduates' perceptions of preparation to labor market transition, while socioemotional and methodological competencies are very close to statistical significance. 
Table 2 - Predictors of graduates' perceptions of the preparation in labor market transition

\begin{tabular}{lcc}
\hline & Coef. & z-values \\
\hline Individual Characteristics & & \\
Female & .310 & $2.08^{*}$ \\
Age & .022 & 1.16 \\
Knowledge and Competencies & & \\
Theoretical contents & .079 & .73 \\
Practical contents & .284 & $3.30^{*}$ \\
Communication competencies & .279 & $2.17^{*}$ \\
Methodological competencies & .202 & 1.94 \\
Interpersonal competencies & -.086 & -.68 \\
Participative competencies & .270 & 1.90 \\
Organizational competencies & -.221 & -1.89 \\
Socioemotional competencies & .170 & 1.95 \\
Generic competencies & -.010 & -.11 \\
Employability competencies & .166 & 1.77 \\
Observations & & \\
Lrx2(12); Lrx2(12) & & 73.562 \\
Prob>x2 & & .000 \\
Log Likelihood & & 566.323 \\
\hline${ }^{*}$ p<.05 & &
\end{tabular}

\section{DISCUSSION AND CONCLUSIONS}

This study was conducted on the premise that students' perceptions of competencies developed during their Higher Education program is an important aspect to the understanding of employability. In general, the obtained data allow us to draw some conclusions about the challenges inherent to the transition from university to Engineering professional contexts.

Comparing the results with the literature presented, a first general conclusion that may be drawn is that engineering graduates are apparently aware of the main competencies required at the moment of professional integration. Indeed, the competencies that emerged as more relevant for the understanding of graduates' perceptions of preparation for labor market transition are coincident with those identified at the literature about professional integration in the Engineering field.

The practical component of the engineering curriculum is presented by the participants as the weakest aspect considering their development during Engineering graduation. On the other hand, this competency emerged as the most relevant to understand graduates' perceptions of preparation to work transition. This means that an effort in improving the practical component of Engineering curriculums would not only benefit graduates' preparation for future professional environment, in a technical sense, but it would also have benefits in terms of graduates' self-beliefs about their preparation to labor market transition. Communication, methodological and socioemotional competencies also emerged as relevant for the understanding of graduates' preparation to labor market transition. These three competencies integrate the set of transversal competencies closely interconnected with practical experience. Being able to use tools and resources and to analyse problems (abilities that describe methodological competencies) is something that require the confrontation with practical problems. Similar results were found in the Medicine field when selfassessed deficits in electrocardiogram interpretation and intubation - which fit our definition of methodological competencies - were associated with an overall feeling of lack of preparedness in doctors with up two years of professional practice [12]. Likewise, communication and socioemotional competencies are usually developed in group situations, which intend to simulate real professional contexts. Therefore, it seems logical that graduates perceive higher levels of preparation when they also self-perceive higher scores in these competencies. 
Analysing the effect of gender in the regression model presented, it can be stated that being a female graduate predicts more positive perceptions of preparation for labor market transition, which apparently contradicts typical gender disparities that negatively affect women in STEM. Although, a previous study [13] developed pointed to a general tendency for the perception of preparation to labor market transition to decrease during the first 24 months of work experience, while male perceptions of preparation tend to increase during such work experiences. Apparently, initial contact with professional contexts affect negatively women' self-beliefs about their transition to the labor market, possibly because of a perceived gender discrimination in professional environments [14]. Therefore, female barriers in the Engineering field may not be an issue particularly present in study programs, but rather a question that assume evidence at the moment of professional integration.

From a practical viewpoint, it should be noted that some of the competencies that appear highlighted as relevant for the transition to professional contexts have been previously related with specific learning methodologies, such as problem-based learning [11], [15]. Further studies should more deeply explore this relation, in order to clearly understand the benefits of innovative learning methods, an aspect that is still somewhat unclear [16]. Returning to the USEM model of employability previously presented, examples of future relevant research questions could be what specific relation is established between innovative learning methodologies, such as problem-based learning and the development of the elements "understanding", "skills", "efficacy beliefs" and "metacognition abilities"? And also, what relation can be established between these elements of the theoretical models and further employability, considering objective aspects (such as time to find a job, wage earned, career promotions) and subjective aspects (such as job satisfaction, self-efficacy in professional contexts, career management skills, etc.)?

Lastly, it should be pointed that graduates reported more positive perceptions about the development of competencies during their Engineering program than regarding their perception of preparation for labor market transition. This may mean that other aspects not considered in this study may assume relevance for the understanding of Engineering graduates' employability. For example, external factors related with graduates' employability, such as the external labour market conditions could be explored in further studies, in an attempt to obtain a more holistic view about Engineering employability in Portugal.

\section{ACKNOWLEDGEMENTS}

This research was supported by the Foundation for Science and Technology (SFRH/BPD/92331/2013).

\section{REFERENCES}

[1] J. Warn and P. Tranter, "Measuring quality in Higher Education: A competency approach," Qual. High. Educ., vol. 7, no. 3, pp. 191-198, 2001.

[2] M. Teijeiro, P. Rungo, and M. J. Freire, "Graduate competencies and employability: The impact of matching firms' needs and personal attainments," Econ. Educ. Rev., vol. 34, pp. 286-295, 2013.

[3] D. Vanhercke, N. De Cuyper, E. Peeters, and H. De Witte, "Defining perceived employability: A psychological approach," Pers. Rev., vol. 43, no. 4, pp. 592-605, May 2014.

[4] M. Salas-Velasco, "Do higher education institutions make a difference in competence development? A model of competence production at university," High. Educ., vol. 68, no. 4, pp. 503-523, Oct. 2014.

[5] A. De Vos, S. De Hauw, and B. I. J. M. Van der Heijden, "Competency development and career success: The mediating role of employability," J. Vocat. Behav., vol. 79, no. 2, pp. 438-447, Oct. 2011.

[6] C. M. Van Der Heijde and B. I. J. M. Van der Heijden, "A competence-based and multidimensional operationalization and measurement of employability," Hum. Resour. Manage., vol. 45, no. 3, pp. 449-476, Jan. 2006.

[7] A. García-Aracil and R. van der Velden, "Competencies for young European higher education graduates: Labor market mismatches and their payoffs," High. Educ., vol. 55, no. 2, pp. 219239, 2008. 
[8] L. D. Pool and P. Sewell, "The key to employability: developing a practical model of graduate employability," Educ. + Train., vol. 49, no. 4, pp. 277-289, 2007.

[9] H. Baytiyeh and M. Naja, "Identifying the challenging factors in the transition from colleges of engineering to employment," Eur. J. Eng. Educ., vol. 37, no. 1, pp. 3-14, Dec. 2011.

[10] N. Spinks, N. Silburn, and D. Birchall, Educating Engineers for the 21st Century: The Industry View, no. March. Oxfordshire: The Royal Academy of Engineering, 2006.

[11] M. Jollands, L. Jolly, and T. Molyneaux, "Project-based learning as a contributing factor to graduates' work readiness," Eur. J. Eng. Educ., vol. 37, no. 2, pp. 143-154, Mar. 2012.

[12] E. B. Ochsmann, U. Zier, H. Drexler, and K. Schmid, "Well prepared for work? Junior doctors' self-assessment after medical education," BMC Med. Educ., vol. 11, no. 1, p. 99, 2011.

[13] S. Monteiro, L. Almeida, and A. García-Aracil, "Graduates' perceptions of competencies and preparation for labour market transition: The effect of gender and work experience during higher education," High. Educ. Ski. Work. Learn., vol. 6, no. 2, pp. 208-220, 2016.

[14] G. A. Maxwell and A. Broadbridge, "Generation y graduates and career transition: Perspectives by gender," Eur. Manag. J., vol. 32, no. 4, pp. 547-553, 2014.

[15] J. N. Warnock and M. J. Mohammadi-Aragh, "Case study: use of problem-based learning to develop students' technical and professional skills," Eur. J. Eng. Educ., vol. 41, no. 2, pp. $142-$ 153, Mar. 2016.

[16] A. Walker and H. Leary, "A Problem Based Learning Meta Analysis: Differences Across Problem Types, Implementation Types, Disciplines, and Assessment Levels," Interdiscip. J. Probl. Learn., vol. 3, no. 1, pp. 6-28, 2009. 